\title{
F-18 Sodium Fluoride Positron Emission Tomography and Computed Tomography Scan
}

National Cancer Institute

\section{Source}

National Cancer Institute. F-18 Sodium Fluoride Positron Emission Tomography and

Computed Tomography Scan. NCI Thesaurus. Code C137816.

An imaging procedure that combines F-18 sodium fluoride PET with a CT scan to overlay activity data onto detailed anatomic images. 